\title{
Why Does Weight Gain Put More Stress on Women?
}

\author{
Young Gyu Cho* \\ Department of Family Medicine, Inje University Seoul Paik Hospital, Inje University College of Medicine, Seoul, Korea
}

\section{See original paper on $\mathbf{3 8 1}$}

In the present issue, Jang et al. ${ }^{1)}$ investigated whether psychological factors such as perceived stress and depression are associated with weight gain among Korean adults using data from the Korea National Health and Nutrition Examination Survey, 2016. The study participants consisted of 3,163 individuals (1,278 men and 1,885 women) aged 19-64 years who had no diseases that might affect weight change. In their study, weight gain was significantly associated with perceived stress (odds ratio, 1.271; 95\% confidence interval, 1.012-1.597) in women, but was not significantly associated with any psychological factors in men. This finding suggests that there is a gender difference in the relationship between weight gain and perceived stress. It should be explained why weight gain is more stressful for women.

Obesity is a multifactorial disease that is influenced by genetic, behavioral, environmental, and sociocultural factors. ${ }^{2)}$ While obesity prevalence has continued to rise over the past decades among Korean men (age-standardized prevalence of obesity: $25.1 \%$ in $1998,42.8 \%$ in 2018 ), it has been reported to have plateaued among Korean women (age-standardized prevalence of obesity: $26.2 \%$ in $1998,25.5 \%$ in 2018). ${ }^{3,4)}$ The gender disparity in obesity prevalence has been widening among Korean adults. Although Korean men and women live in the same obesogenic environment, Korean women may be disproportionately under intense socio-cultural pressure not to be overweight. ${ }^{5)}$ Accordingly, Korean women are more likely to overestimate their body weight than Korean men, which leads to weight control attempts. ${ }^{6)}$ In Korean society, a significant number of underweight women try to lose or maintain their body weight for better appearance. ${ }^{7)}$

Obese individuals encounter weight-based prejudice and discrimination in various aspects of their daily lives, including employment, income, education, interpersonal relationships, health care, and media. Korean society is known to have an extremely high level of weight-based bias. Marini et al. ${ }^{8)}$ reported that Koreans had the strongest preference for thin people over overweight people among all citizens of 71 nations. Women are more likely to experience weight-based discrimination compared to men. Sarlio-Lähteenkorva and Lahelma ${ }^{9)}$ reported that obesity was associated with unemployment, low income, and lack of close friends in Finnish women but was not problematic for Finnish men. In a society where weight stigma is pervasive, overweight women are expected to obtain lower occupational attainment and lower earnings than those of thin women. It is noteworthy that women's wages begin to decrease at weights much lower than conventional thresholds for overweight or obesity. ${ }^{10)}$ Therefore, even thin women stress about weight gain.

In a society where slender bodies are recognized as good and overweight bodies as evil, weight stigma is prevalent and weight bias is internalized. ${ }^{11)}$ Since the social norms regarding ideal body weight are stringent for women, maintaining a socially acceptable body size is more stressful for women. ${ }^{12)} \mathrm{A}$ multidisciplinary group of international experts developed a joint consensus statement with recommendations to eliminate weight bias. ${ }^{13)}$ The Korean Society for the Study of Obesity also endorsed the statement. They stated that some public health campaigns stigmatize obese individuals to motivate behavioral change and encourage them to lose their body weight, but these strategies may increase weight-based discrimination and lead to unwanted effects such as exercise avoidance, consumption of unhealthy foods, increased sedentary behaviors, and increased weight gain. Therefore, these stigmatizing approaches to promote anti-obesity bias should 
be banned and policies against weight-based discrimination should be established.

\section{CONFLICT OF INTEREST}

No potential conflict of interest relevant to this article was reported.

\section{ORCID}

Young Gyu Cho: https://orcid.org/0000-0003-1017-8884

\section{REFERENCES}

1. Jang HJ, Kim BS, Won CW, Kim SY, Seo MW. The relationship between psychological factors and weight gain. Korean J Fam Med 2020;41:3816.

2. Qasim A, Turcotte M, de Souza RJ, Samaan MC, Champredon D, Dushoff J, et al. On the origin of obesity: identifying the biological, environmental and cultural drivers of genetic risk among human populations. Obes Rev 2018;19:121-49.

3. Shin HY, Kang HT. Recent trends in the prevalence of underweight, overweight, and obesity in Korean adults: the Korean National Health and Nutrition Examination Survey from 1998 to 2014. J Epidemiol 2017;27:413-9.

4. Korea Centers for Disease Control and Prevention. Korea health statistics 2018: Korea National Health and Nutrition Examination Survey (KNHANES VII-3) [Internet]. Cheongju: Korea Centers for Disease Control and Prevention; 2018 [cited 2020 Oct 19]. Available from:
https://knhanes.cdc.go.kr/knhanes/sub04/sub04_03.do?classType=7. 5. Rhee SY, Park SW, Kim DJ, Woo J. Gender disparity in the secular trends for obesity prevalence in Korea: analyses based on the KNHANES 1998-2009. Korean J Intern Med 2013;28:29-34.

6. Noh JW, Kwon YD, Yang Y, Cheon J, Kim J. Relationship between body image and weight status in east Asian countries: comparison between South Korea and Taiwan. BMC Public Health 2018;18:814.

7. Choi OJ, Cho YG, Kang JH, Park HA, Kim KW, Hur YI, et al. Weight control attempts in underweight Korean adults: Korea National Health and Nutrition Examination Survey, 2007-2010. Korean J Fam Med 2013;34:393-402.

8. Marini M, Sriram N, Schnabel K, Maliszewski N, Devos T, Ekehammar $\mathrm{B}$, et al. Overweight people have low levels of implicit weight bias, but overweight nations have high levels of implicit weight bias. PLoS One 2013;8:e83543.

9. Sarlio-Lahteenkorva S, Lahelma E. The association of body mass index with social and economic disadvantage in women and men. Int J Epidemiol 1999;28:445-9.

10. Fikkan JL, Rothblum ED. Is fat a feminist issue?: exploring the gendered nature of weight bias. Sex Roles 2012;66:575-92.

11. Nutter S, Russell-Mayhew S, Saunders JF. Towards a sociocultural model of weight stigma. Eat Weight Disord 2020 May 27 [Epub]. https://doi.org/10.1007/s40519-020-00931-6.

12. Brewis AA, Han SY, SturtzSreetharan CL. Weight, gender, and depressive symptoms in South Korea. Am J Hum Biol 2017;29:e22972.

13. Rubino F, Puhl RM, Cummings DE, Eckel RH, Ryan DH, Mechanick JI, et al. Joint international consensus statement for ending stigma of obesity. Nat Med 2020;26:485-97. 